\title{
ALGUNOS COMENTARIOS SOBRE LA PRESUNCIÓN DE VALIDEZ DE LOS ACTOS ADMINISTRATIVOS EN LA LEY DE BASES DE LOS PROCEDIMIENTOS ADMINISTRATIVOS
}

Some comments on the presumption of the validity of the administrative acts in the base law of the administrative procedures

Álvaro Roberto Delgado Lara* UNIVERSIDAD BERNARDO O'HIGGINS SANTIAGO, CHILE

\footnotetext{
* Doctorando en Programa de Doctorado de Ciencias Sociales y Jurídicas de la Universidad de Córdoba (España). Correo electrónico: <alvaro.delgado17@gmail.com>. Este trabajo es parte de mi tesis doctoral que se encuentra en actual desarrollo.
}

Artículo recibido el 4 de abril de 2018 y aceptado para publicación el 30 de mayo de 2018. 
RESUMEN: Este trabajo inicia con la afirmación de que presunción de legalidad y presunción de validez de los actos administrativos, aunque se suelan usar como equivalentes, en estricto rigor no son un mismo instituto. Para luego sostener que, aun cuando la legislación chilena ha expresado que los actos administrativos gozan de una presunción de legalidad, del estudio respectivo, resulta que la interpretación correcta es que se ha consagrado la institución de la presunción de validez. Con lo cual, se analiza en qué consiste esta última, como también cuál es su inicio y su conclusión. Finalmente, se expone cómo se debe concebir la fuerza vinculante que emana de la presunción de validez respecto a la Administraciones Públicas y los Tribunales de Justicia.

PAlabras Clave: actos administrativos, presunción de legalidad, presunción de validez.

ABSTRACT: This work begins with the assertion that the presumption of legality and the presumption of validity of administrative acts, although they are generally used as equivalents, strictly speaking, are not the same institute. To then argue that, although in Chilean legislation it has been expressed that administrative acts enjoy a presumption of legality, the corresponding study, shows that the correct interpretation is that the institution of the presumption of validity has been established. With which, we analyze what is the presumption of validity, as well as what is its beginning and conclusion. Finally, we explain how to conceive the binding force that emanates from the presumption of validity with respect to the public administrations and the courts of Justice.

KEYWORDS: administrative acts, presumption of legality, presumption of validity. 


\section{INTRODUCCIÓN}

Se afirma que la validez del acto administrativo no es otra cosa que su adecuación al Derecho o al ordenamiento jurídico en su conjunto'. Y como bien lo completa Esteve aquello es "una condición que en pura lógica jurídica resulta básica y fundamental para que un acto pueda desplegar efectos es que éste sea válido, que se ajuste al ordenamiento jurídico"2. De modo que la legitimidad y conservación de los efectos del acto dependerán de que este último sea válido. Ahora bien, el Derecho chileno no entra a lidiar si el acto es válido o no, sino que dispone que los actos administrativos, en principio, son válidos, es decir presume su validez. Es así que la Ley $\mathrm{n}^{\circ}$ 19.880, de 2003, de Bases de los Procedimientos Administrativos (en adelante LBPA), en su artículo $3^{\circ}$, luego de conceptualizar los actos administrativos, dispone que estos últimos "gozan de una presunción de legalidad, de imperio y de exigibilidad frente a sus destinatarios, desde su entrada en vigencia, autorizando su ejecución de oficio por la autoridad administrativa, salvo que mediare una orden de suspensión dispuesta por la autoridad administrativa dentro del procedimiento impugnatorio o por el juez, conociendo por la vía jurisdiccional".

Como ya se puede anticipar, este es un tema bastante complejo entre todos aquellos que conforman el Derecho Administrativo, pues su presencia acarrea importantes consecuencias, tanto para las administraciones públicas, los tribunales de Justicia y los administrados. Así, por ejemplo, García de EnTERría y FernándeZ ${ }^{3}$ señalan que la existencia de esta institución jurídica no sólo permite que los actos administrativos, a pesar de incurrir en ilegalidades e irregularidades, desplieguen todos sus potenciales efectos mientras no se demuestre y se declare por el órgano respectivo su invalidez, sino que además desplaza al particular la carga de impugnar tales actos, pues el ordenamiento jurídico parte de la premisa que el acto administrativo es válido y por consiguiente la producción de sus efectos se consideran legítimos ${ }^{4}$.

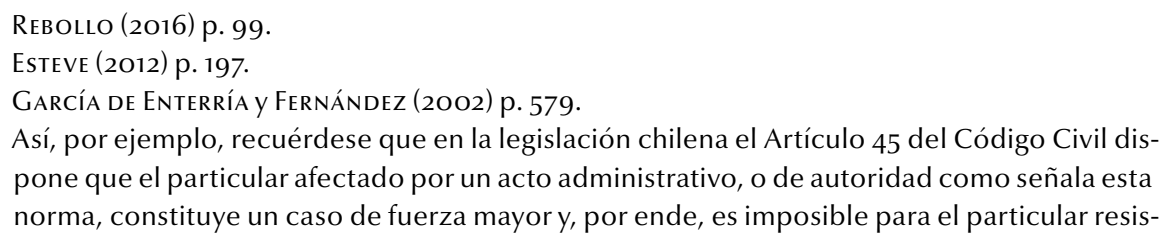
pone que el particular afectado por un acto administrativo, o de autoridad como señala esta norma, constituye un caso de fuerza mayor y, por ende, es imposible para el particular resis- 
Por lo mismo, en el sistema jurídico chileno la presunción de validez ha sido un asunto algo controvertido, de ahí que es posible encontrar tanto aquellas doctrinas que han criticado la existencia de la presunción de validez o su actual constitucionalidad ${ }^{5}$, como también aquellas que la han defendido, aun cuando no existía texto legal expreso que la contemplara $^{6}$. Pero lo cierto es que, a nuestro juicio, con la entrada en vigencia de la LBPA tal disyuntiva se zanja, pues la presunción de validez o, si se sigue la fórmula prescriptiva que emplea esta misma ley, la presunción de legalidad, se consolida normativamente como una prerrogativa ${ }^{7}$ pro- $^{-}$ pia e inherente de todos los actos administrativos ${ }^{8}$ y que, tal como lo ha entendido el Tribunal Constitucional chileno, se encuentra en armonía con la Constitución Política de la República y con los principios propios de un Estado de Derecho'.

En este orden de ideas, el presente trabajo no busca discurrir sobre la constitucionalidad o inconstitucionalidad de la presunción de validez, sino que parte de la base que la incorporación y legitimidad de la presunción de validez de los actos administrativos en el ordenamiento jurídico chileno es una cuestión que nos resulta indubitada y de ahí que aquello que ahora nos convoca es dilucidar y analizar ciertas interrogantes que se derivan de su correlativa existencia y aplicación en el sistema jurídico nacional.

En tal sentido, aquello que primero nos requiere dice relación con que la mencionada LBPA ha sido elaborada muy cercana al Derecho hispano, el que por lo demás le ha servido de modelo ${ }^{10}$, mas no es una copia

tirse a su acatamiento, mientras no sus efectos sean suspendidos o este sea eliminado por las vías destinadas al efecto.

5 Cfr. Aróstica (1991) pp. 1-7, y Soto (1996) p. 161. Más recientemente y con la LBPA ya vigente, Soto (2010) pp. 7-14 y Riveros (2006) pp. 117-124.

6 Cfr. Madariaga (1993) p. 108, Silva (1995) p. 121 y Marín (2002).

7 Aguerrea (2003) p. 45.

8 Moraga (2010) p. 98.

9 El Tribunal Constitucional, sobre el pronunciamiento de oficio sobre la inconstitucionalidad del inciso primero del artículo 171 del Código Sanitario (2009, rol n ${ }^{\circ} 1345-2009$ ) considerando $14^{\circ}$, ha señalado que “(...) la presunción de legalidad de los actos de la administración, recogida expresamente en una norma legal, resulta concordante con fines constitucionales, como los ya referidos en el considerando anterior. La vigencia misma de un Estado de Derecho se haría francamente dificultosa si no se partiera de este supuesto y los actos de la Administración no tuvieran valor hasta tanto no fueran impugnados y validados en sede judicial o por la vía de otros mecanismos de control".

Recuérdese que, conforme a la historia de la LBPA, la legislación española constituye uno de 
idéntica y por ello es posible percatarse que la LBPA utiliza el enunciado presunción de legalidad en vez de la fórmula presunción de validez que emplea la legislación española ${ }^{11}$, con lo cual se nos genera la primera interrogante relativa a determinar si ambas prescripciones normativas significan lo mismo y, por ende, sus efectos serán similares u obedecen a entidades jurídicas disímiles. Luego, y después de asentado que la LBPA, aun cuando con un léxico distinto en relación a su homónima hispana, en realidad ha consagrado el mismo instituto jurídico, estimamos relevante continuar con la explicación de aquello en lo que consiste la presunción de validez, en el que establecemos que esta institución es más que una mera suposición de legalidad y por ende permea toda la teoría de los actos administrativos. Agotado lo anterior, derivamos a dos incógnitas más. Una tiene relación con el inicio de la presunción de validez en Chile, que como lo hemos indicado -según la LBPA- ocurre una vez que el acto entra en vigencia, y en la que nos preguntamos si un acto administrativo que ha sido dictado, pero no está vigente, deberá someterse al procedimiento de invalidación contemplado en la LBPA, o más bien, conforme a lo que afirmamos, bastará el simple retiro del acto, sin mayores trámites, pues el acto aún no está revestido con la presunción de validez. La otra interrogante tiene relación con la pérdida de la presunción de validez, en el sentido de discernir cuál es el medio para ponerle fin, pues-como se sabe- un acto administrativo puede ser eliminado de diversas formas, pero en nuestra opinión la presunción de validez solamente se destruirá con la respectiva declaración de invalidez.

Finalmente, se nos plantea la incógnita de si las administraciones y los tribunales de Justicia se encuentran vinculados por la presunción de validez de los actos administrativos y en qué medida. A nuestro juicio, la respuesta se encamina por distinguir a las administraciones públicas por un lado y a

los principales modelos tenidos a la vista por el legislador chileno para su elaboración. Biblioteca del Congreso Nacional (2003) pp. 69, 99, 129, 135 y 179. Asimismo, varios autores lo han evidenciado, v.g. Bocksang (2003) p. 18, Pierry (2005) p. 4 y Camacho (2013) p. 8o. Por consiguiente, entendemos que el estudio de dicha legislación, como también de la doctrina que la explica, es un elemento concluyente para la correcta comprensión del asunto en análisis, como también el de toda la teoría de los actos administrativos en el sistema jurídico chileno.

11 La actual Ley española n ${ }^{\circ}$ 39, de 2015, en su Artículo 39.1 dispone que "Los actos de las administraciones públicas sujetos al derecho administrativo se presumirán válidos y producirán efectos desde la fecha en que se dicten, salvo que en ellos se disponga otra cosa" (anótese que esta ley es la continuadora de la derogada Ley $n^{\circ} 30$, de 1992, y que el citado artículo estaba redactado en términos idénticos y fue el que tuvo a la vista el legislador chileno). 
los jueces por el otro, pues sostenemos que la presunción de validez liga a las administraciones públicas con la misma fuerza que a los particulares, es decir el acto administrativo las vincula y no pueden dejar de cumplirlo, salvo la respectiva orden de suspensión y hasta que el acto sea declarado inválido por el órgano competente para ello, pero dicha sujeción respecto a los jueces opera de manera distinta, ya que como estos últimos son los llamados en definitiva a disipar sobre si un acto administrativo es válido o no, es decir resolver sobre si deberá subsistir o se destruye la presunción de validez, esta última los vincula en el sentido que estructura el objetivo principal del juicio, es decir resolver sobre el mérito o conveniencia de suspender los efectos del acto impugnado, en caso que así sea requerido, como también la constatación de que el acto carece de validez.

En este sentido, el trabajo se estructura, en primer lugar, con la determinación del enunciado presunción de legalidad de la LBPA como equivalente a la expresión presunción de validez. Luego, y en segundo lugar, nos concierne establecer en qué consiste esta institución. En tercer lugar, sobre su inicio y su fin. En cuarto lugar nos interesa destacar el alcance de la fuerza vinculante de la presunción de validez con respecto a la misma Administración y el régimen que los diferencia con respecto a los tribunales de Justicia. Para finalizar con las respectivas conclusiones.

\section{LA EXPRESIÓN PRESUNCIÓN DE LEGALIDAD DE LA LBPA COMO EQUIVALENTE A LA EXPRESIÓN PRESUNCIÓN DE VALIDEZ}

La LBPA, en su Artículo $3^{\circ}$, expresa que los actos administrativos gozan de una presunción de legalidad desde que entran en vigencia ${ }^{12}$; sin embargo, aun cuando se estima que ésta no es la expresión más adecuada - pues, como se explica a lo largo de este trabajo, no refleja la real dimensión de la institución en estudio, sino que por el contrario puede inducir a errores-, es posible afirmar que el precepto legal solamente no acierta en

12 LBPA, Artículo 3․ "Los actos administrativos gozan de una presunción de legalidad, de imperio y exigibilidad frente a sus destinatarios, desde su entrada en vigencia, autorizando su ejecución de oficio por la autoridad administrativa, salvo que mediare una orden de suspensión dispuesta por la autoridad administrativa dentro del procedimiento impugnatorio o por el juez, conociendo por la vía jurisdiccional". 
cuanto al léxico empleado para describir la institución que en realidad instituye. De ahí que asentamos que aquello que en su correcto contexto contempla el mencionado Artículo $3^{\circ}$ es la institución de la presunción de validez, es decir "aquella cualidad de los actos administrativos en cuya virtud existe el deber de actuar y decidir partiendo de la premisa de que los actos administrativos son válidos en tanto no se declare su nulidad o sean anulados ${ }^{\prime \prime 13}$ y no una mera suposición de que el acto administrativo una vez vigente se considera acorde con la ley, tal como se podría desprender de una interpretación basada únicamente en el tenor literal de la citada disposición legal.

En efecto, REBOLLo afirma que la designación más adecuada para referirse a la institución precedentemente descrita es la de presunción de validez, la cual en estricto rigor no puede considerarse como un equivalente idéntico a la expresión presunción de legalidad ${ }^{14}$. Le hallamos la razón, pues partiendo del supuesto que aquello que se presume son entidades distintas, es decir legalidad y validez no son lo mismo, también existen fundamentos para dirimir que presunción de legalidad y presunción de validez no son equivalentes. Efectivamente, legalidad en su sentido más puntual quiere significar una mera conformidad con la normativa que lo regula. En cambio, la validez va más allá, pues además implica la adecuación del acto a otros elementos o factores como son aquellos intereses y valores relevantes que se extraen del contenido explícito o intrínseco de las diversas reglas que componen el ordenamiento jurídico y no sólo de aquellas normas que directamente regulan la elaboración del acto administrativo en particular. Así, CANO explica que sin bien "la validez designa una relación de conformidad o adecuación del acto con el ordenamiento, con las normas que regulan su producción, estas normas no están integradas únicamente por las denominadas reglas secundarias o que confieren poderes (o competencia, según una terminología más próxima a nosotros), sino también por normas primarias o de mandato, esto es, normas que establecen cómo han de ser usados tales poderes por parte de los órganos del Estado (... $)^{\prime \prime 15}$. Ejemplo de norma primaria en el ordenamiento chileno es el inciso $2^{\circ}$ del Artículo $1^{\circ}$ de la Constitución Política de la República, que dispone que "El Estado está al servicio de la persona humana

13 Rebollo (2005) p. 591.

14 Ibídem, p. 596.

15 Cano (2005) p. 8. 
y su finalidad es promover el bien común, para lo cual debe contribuir a crear las condiciones sociales que permitan a todos y a cada uno de los integrantes de la comunidad nacional su mayor realización espiritual y material posible, con pleno respeto a los derechos y garantías que esta Constitución establece". En este sentido, un acto administrativo elaborado en contra del interés general o bien común, por mucho que haya respetado las normas precisas que regulan su confección, se deberá declarar inválido por el órgano competente, pues se ha contravenido a la citada norma primaria. O, contrario sensu, un acto administrativo será legal si el órgano que lo dicta es competente, si actúa conforme al procedimiento establecido al efecto, si no transgrede en su contenido una norma que lo regule en el fondo, etc., pero será válido en la medida que ese acto además, por ejemplo, se ajuste al principio de proporcionalidad, que en palabras de BocANEGRA se refiere a que "el acto debe ser adecuado a los fines que persigue, esto es, que debe ser idóneo, necesario y guardar relación con el fin propuesto"16, o que el acto sea dictado con sujeción al principio de precisión, el cual "impone, justamente, que el acto tenga un contenido preciso y consecuente, de forma que el destinatario pueda conocer sin lugar a duda qué es lo que el órgano ha declarado"17.

Inversamente, tampoco son lo mismo invalidez e ilegalidad, ya que la ilegalidad dice relación con la simple confrontación del acto con el ordenamiento jurídico, en cambio la invalidez es la consecuencia que el mismo ordenamiento prevé y en el que se consideran los aludidos factores adicionales a la mera ilegalidad, y que según su análisis aconsejan la determinación de eliminar o no un acto administrativo ilegal, por lo cual es posible encontrar actos administrativos ilegales pero válidos. De ahí que en estos últimos casos lo que se habrá destruido es únicamente la presunción de legalidad del acto administrativo, pues como se puede comprender, tal acto adolece de alguna ilegalidad, pero si esa ilegalidad descubierta no es invalidante, producto de la apreciación que el mismo ordenamiento jurídico prevé, a la mera infracción de la legalidad, y que la autoridad administrativa o el juez deberán analizar caso a caso, el acto administrativo aunque ilegal seguirá presumiéndose válido y, por consiguiente, seguirá gozando de tal presunción, y continuará con la producción de todos sus respectivos efectos ${ }^{18}$.

\begin{tabular}{ll}
\hline 16 & Bocanegra (2012) p. 92. \\
17 & Ídem. \\
18 & Rebollo (2005) p. 596.
\end{tabular} 
Ahora bien, aunque ajena, esta reflexión es perfectamente trasladable al Derecho chileno, pues concebimos que explica mejor aquellas situaciones en las que es posible encontrar que un acto administrativo pierda su presunción de legalidad, pero no la de validez. Así, por ejemplo, ocurre en el caso de las ilegalidades no invalidantes contempladas en el Artículo 13 de la LBPA. Esta norma de partida nos da la razón, pues textualmente se refiere a validez y no a legalidad, ya que dispone que "el vicio de procedimiento o de forma sólo afecta la validez del acto administrativo cuando recae en algún requisito esencial del mismo, sea por su naturaleza o por mandato del ordenamiento jurídico, y genera perjuicio al interesado". Asimismo, del citado precepto legal se puede observar que aquello que el ordenamiento jurídico chileno efectivamente contempla es la institución de la presunción de validez de los actos administrativos en su estricto rigor, aun cuando el léxico utilizado sea el de presunción de legalidad. Al respecto, Vergara explica que de la interpretación del Artículo 13 de la LBPA se desprende que existen vicios o ilegalidades que no revisten la gravedad suficiente para afectar la validez del $\operatorname{acto}^{19}$ y que, tal como bien lo precisa BERMÚDEZ, esto se debe a que la LBPA exige la concurrencia de ilegalidades lo bastantemente trascendentes para afectar la validez del acto administrativo ${ }^{20}$. Por ello, y con respecto a la dicotomía presunción de validez/presunción de legalidad que estamos discutiendo, lo precedentemente señalado viene a significar que aunque cotejada alguna contradicción de carácter formal o procedimental entre el acto administrativo y alguna norma que lo regule, sólo implicará que el mencionado acto se torna ilegal, por estar obviamente en incumplimiento de dicha norma, con lo cual el susodicho acto perderá su presunción de legalidad, pues ya se evidenció una determinada ilegalidad, pero si esta última, como vicio que es, no es de carácter esencial ni ha generado un perjuicio al interesado, no corresponderá invalidar el acto ilegal y por ende no perderá su presunción de validez ni sus correlativos efectos, es decir el acto, aun cuando es ilegal, se le seguirá presumiendo válido y, por tanto, se deberá seguir acatando. De ahí que la distinción entre la presunción de validez y presunción de legalidad, en su estricto rigor, no puede ser considerada antojadiza ni bizantina.

Para mayor abundamiento, existe otro caso destacable que demuestra la distinción entre presunción de legalidad y presunción de validez en la

19 Vergara (2013) p. 275.

20 Bermúdez (2010) p. 108. 
LBPA. Es aquel contemplado en su Artículo 12, por el que se consagra el principio de abstención de los funcionarios públicos en determinados casos que la misma ley indica, pero - como bien lo explica MILLAR- la infracción al principio de abstinencia, a pesar de constituir una ilegalidad, no afectará imperiosamente la validez del acto, sino que solamente la responsabilidad disciplinaria del infractor ${ }^{21}$, tal como se desprende del inciso $3^{\circ}$ del mencionado artículo, que dispone que "(...) la actuación de autoridades y los funcionarios de la Administración en los que concurran motivos de abstención no implicará, necesariamente, la invalidez de los actos en que hayan intervenido. La no abstención en los casos en que proceda dará lugar a responsabilidad (...)". Por consiguiente, aquel acto administrativo en cuya elaboración ha intervenido una autoridad o funcionario inhábil, por regla general, configura una mera ilegalidad, pues se ha desatendido un mandato expreso del legislador. Pero en la medida que así sea calificado, implicará la invalidez del acto y la correlativa extinción de la presunción de validez.

Es por ello que insistimos que la presunción de validez y la presunción de legalidad, en estricto rigor, no son el mismo instituto, ni pueden serlo, aunque suelen estar extremadamente próximas una de otra y su distinción pueda generar alguna que otra duda. Sin embargo, como bien lo evidencia el mismo Rebollo ${ }^{22}$, y aun cuando no es lo más conveniente, pues creemos que el incorrecto uso de las palabras solo trae aparejado desconcierto ${ }^{23}$, ocurre que los distintos ordenamientos jurídicos y los diversos autores que han bosquejado sobre el asunto utilizan una gran variedad de términos, tal como son el de presunción de legalidad o de legitimidad y lo emplean como sinónimos al de presunción de validez.

21 Millar (2008) p. 199.

22 Rebollo (2005) pp. 592 y 596.

23 Así ocurre, por ejemplo, en la Corte Suprema, Sociedad Química y Minera de Chile S.A. contra Comisión de Evaluación Ambiental de la Región de Tarapacá (2015, rol n² 21.993-2014), considerando $24^{\circ}$, en la cual la Corte Suprema ha expresado que: “(...) El presupuesto recién aludido - de dotar de contenido y fundar adecuadamente el interés hecho valer-resultaba indispensable como quiera que la solicitud invalidatoria persigue poner en movimiento un procedimiento tendiente a desvirtuar la presunción de legalidad, validez y legitimidad de que está dotado per se un acto administrativo. (...)". Es decir, aquí no se pude dilucidar con certeza si se están utilizando todos los vocablos como equivales entre sí o si aquello que menciona la Corte Suprema son tres presunciones distintas, pero relacionadas entre sí. 
En efecto, esta diversidad de vocablos ha sucedido inclusive en el mismo Derecho español, así Boquera con referencia a la presunción de validez, señalaba que "Ios actos administrativos, como todo, deben ser legales y se presume que lo son (...)"24. En el mismo sentido, así también acontece en la legislación argentina, la cual en el artículo 12 de la Ley $\mathrm{N}^{\circ}$ 19.549, de 1972, establece que "el acto administrativo goza de presunción de legitimidad (...)", pero que según su doctrina dicho enunciado contempla en realidad a la presunción de validez del acto administrativo, la que como tal rige mientras su posible nulidad no haya sido declarada por autoridad competente ${ }^{25}$.

En cuanto a la doctrina chilena, ésta también utiliza diversos vocablos para referirse a la presunción de validez. Así, también suele emplear las expresiones de presunción de legalidad o legitimidad, tal como ocurre en obras de Olguín ${ }^{26}$, MADARIAGA ${ }^{27}$ o BermúdeZ ${ }^{28}$. Igualmente es posible hallar la denominación de presunción de juridicidad ${ }^{29}$. Pero, lo cierto es que de acuerdo a la representación que tales autores dan sobre la institución, se aprecia que en contexto lo que describen es la presunción de validez en los términos ya explicados.

De igual forma ha ocurrido en la jurisprudencia, en donde la Corte Suprema de Justicia, en algunas de sus sentencias, ha utilizado los conceptos de presunción de validez y presunción de legalidad como vocablos semejantes ${ }^{30}$.

24 Boquera (1983) p. 1003. Esto lo expresaba así, aun cuando en ese entonces la antigua legislación española sobre la materia (Ley de Procedimiento Administrativo de 1958), en su artículo 45, ya aludía al concepto de validez y no al de legalidad, pues disponía que "Ios actos de la Administración serán válidos y producirán efectos desde la fecha en que se dicten, salvo que en ellos se disponga otra cosa".

25 Dromi (2008) p. 117.

26 Olguín (1961) p. 24.

27 Madariaga (1993) p. 108.

28 BeRmúdez (2011) p. 124.

29 Moraga (2010) p. 97.

30 Así ha ocurrido, por ejemplo, en sentencia de la Corte Suprema, Ilustre Municipalidad de La Reina contra Inversiones Aguas Claras S. A. (2015, rol n 6.237-2015), se observa, en el considerando $12^{\circ}$, que la Corte Suprema ha empleado el enunciado presunción de legalidad y, posteriormente en el considerando $15^{\circ}$, ha utilizado sobre el mismo asunto el enunciado presunción de validez, a saber: "Décimo segundo: Que resulta pertinente hacerse cargo de la denunciada vulneración de los artículos 1698 y 1700 del Código Civil. Al respecto cabe tener presente, en relación al primero, que los falladores desestimaron las excepciones de que se trata, teniendo en consideración que el Certificado de Deuda que sirve de título a la ejecución goza de mérito ejecutivo y, además, de la presunción de legalidad establecida en el artículo 3 de la Ley $N^{\circ} 19.880$, a lo que 
Por consiguiente, de lo precedente queda de manifiesto que presunción de legalidad y presunción de validez, en recto orden, no son un mismo instituto, aunque la doctrina, la jurisprudencia y las normas en algunos casos usan ambos enunciados indistintamente, como si se tratasen de sinónimos. Asimismo, en dogma con el elemento lógico de interpretación de la ley, que indica el artículo 22 del Código Civil ${ }^{31}$, es decir en armonía y en relación con todas las normas que componen la LBPA, la interpretación correcta que se debe dar de su artículo $3^{\circ}$ es que el legislador ha situado en el ordenamiento jurídico chileno a la institución de la presunción de validez de los actos administrativos en su estricto rigor, no obstante se haya expresado con un léxico inconveniente, a nuestro parecer, a la presunción de legalidad.

\section{EN LO QUÉ CONSISTE LA PRESUNCIÓN DE VALIDEZ}

De partida, ni definición ni concepto sobre lo qué es la presunción de validez es posible hallar en la legislación chilena o en la hispana que le ha servido de modelo. Ante esta incógnita, y para dar inicio a este apartado, reiteramos la definición que nos otorga Rebollo, la cual expresa que "la presunción de validez es la cualidad de los actos administrativos en cuya virtud existe el deber de actuar y decidir partiendo de la premisa de que los actos administrativos son válidos en tanto no se declare su nulidad o sean anulados ${ }^{\prime \prime 2}$. Pues, a nuestro juicio, el correcto significado de esta institución se refleja en tal definición. Así, podemos asentir que

añadieron que una de tales defensas no fue debidamente fundada y que la demandada no demostró, como lo alegó al oponer sus defensas, que su parte dejó de realizar la actividad lucrativa cuyo ejercicio genera el pago de la patente cobrada en la especie (...)". "Décimo quinto: Que asílas cosas, y no habiéndose enervado oportunamente la presunción legal de validez del acto administrativo posteriormente impugnado, corresponde reconocerle su plena validez". En el mismo sentido, se puede observar la Corte Suprema, Sociedad de Proyectos y Servicios Ingeniería Limitada contra Gobierno Regional de Tarapacá (2015, rol n 1.126-2015), en la cual la Corte Suprema en vez de seguir el tenor literal del Artículo $3^{\circ}$ de la LBPA, es decir la presunción de legalidad, ha usado el enunciado de la presunción de validez, a saber: "(...) los sentenciadores de segunda instancia quebrantaron, además, lo prevenido en el artículo 3 de la Ley $n^{\circ}$ 19.880, puesto que con ello desconocieron la presunción de validez y la ejecutabilidad de oficio por la autoridad administrativa de los actos administrativos" (considerando $10^{\circ}$ ).

31 Código Civil, Artículo 22. "El contexto de la ley servirá para ilustrar el sentido de cada una de sus partes, de manera que haya entre todas ellas la debida correspondencia y armonía (...)".

32 Rebollo (2005) p. 591. 
la presunción de validez se erige como una cualidad propia de los actos administrativos, que los caracteriza y diferencia, ya que dicha cualidad no se replica en otros actos jurídicos, como son aquellos emitidos por los particulares, todos los cuales a lo más solamente afectarán a quienes se hallan obligados por aquellos y, aun así, los actos jurídicos de los particulares no surgirán a la vida del Derecho con la prerrogativa de imponer su cumplimiento por sí mismos, sino que siempre requieren que sea un juez quien disponga su observancia en caso de resistencia o en el evento que se cuestione su legalidad ${ }^{33}$. Pero, mucho más relevante que aquello, es porque el efecto propio de la presunción de validez es la de revestir a los actos administrativos con una fuerza vinculante ${ }^{34}$, es decir impone, tanto para las mismas administraciones públicas como para los particulares, un deber de acatamiento de los efectos producidos por el acto administrativo, que se justifica con la circunstancia de que al dar por sentado que el acto es válido, implica que este se deberá cumplir, en tanto no sea destruido por alguno de aquellos mecanismos jurídicos que el ordenamiento jurídico ofrezca para declarar su invalide $z^{35}$. Asimismo lo ha razonado la jurisprudencia administrativa de la Contraloría General de la República ${ }^{36}$, la que ha sostenido en diversos dictámenes ${ }^{37}$ que la presunción de validez establece que el acto administrativo respectivo debe ser obedecido tanto por las autoridades como por los particulares a quienes afecta, sin perjuicio de que con posterioridad a su entrada en vigencia, la autoridad administrativa, de oficio o a petición de parte, o el juez en su caso dispongan invalidar tales decisiones cuando nuevos elementos de juicio o antecedentes demuestran su contrariedad con el Derecho.

Ahora bien, aunque parezca un juego de palabras, cabe precisar que validez y presunción de validez no son lo mismo, como tampoco son condiciones de la eficacia del acto administrativo.

En efecto, en primer lugar es menester apuntar que un acto es válido en la medida que efectivamente se ajuste a las normas que regulan su producción jurídica, como también aquellas reglas que establecen cómo han de ser usados tales poderes por parte de los órganos de las administraciones

33 Esteve (2012) p. 200.

34 Rebollo (2005) p. 592.

35 CANO (2004) p. 186.

36 En adelante, "CGR".

37 CGR, v.g. dictámenes $n^{\circ} 44.041$ de 2005 y 29.826 de 2006. 
públicas $^{38}$. En segundo lugar, y tal como ya lo hemos explicado, la presunción de validez no significa que el acto necesariamente sea válido, sino que ésta sólo configura una suposición inicial de validez, que, atribuida por el ordenamiento jurídico a todos los actos administrativos, impone que estos últimos se deban acatar, hasta que no sean debidamente invalidados. En ese sentido se puede vislumbrar que ni la validez ni la presunción de validez son condiciones para la eficacia de los actos administrativos, esto quiere decir que los efectos jurídicos del acto no surgen porque el acto es válido ni porque se presume válido, sino que la eficacia del mismo es consecuencia de otra previsión del ordenamiento jurídico y que, en el Derecho que nos ocupa, se halla en el Artículo 51 de la LBPA. Así, esta norma viene a establecer que los actos administrativos causan inmediata ejecutoriedad y producirán sus efectos jurídicos desde su notificación o publicación, según corresponda, con lo cual puede ocurrir que un determinado acto no sea ciertamente válido, pero si fue publicitado producirá igualmente sus concernientes efectos jurídicos.

Pero entonces, ¿ ¿cómo se vincula la presunción de validez con la eficacia del acto? Sobre el particular nos inclinamos por seguir la reflexión que hace Rebollo, quien precisa que "la presunción de validez expresa la fuerza del acto administrativo, no su eficacia. No obstante, se relaciona con la eficacia: obliga desde el principio a respetar los efectos propios del acto (...)"39. Es decir, el acto es eficaz porque tiene la cualidad para producir sus respectivos efectos, así por ejemplo fue correctamente notificado, pero el imperativo que dispone acatar tales efectos es consecuencia de que el acto se presume válido. Por eso mismo, García de Enterría y FERNÁNDEZ han sintetizado correctamente que el efecto propio de la presunción de validez es que ésta "permite al acto desplegar todos sus posibles efectos en tanto no se demuestre su invalidez (...)" ${ }^{\prime \prime 4}$.

Siendo así, se puede compendiar que el propósito de la instauración de la presunción de validez de los actos administrativos, es que estos últimos sean obedecidos por sus destinatarios, inclusive cuando el acto administrativo presente vicios o defectos que sean causales de nulidad de pleno Derecho, que son los más graves, aquel acto por muy mefítico que sea, hasta que no sea debidamente invalidado igualmente vincula. Es más,

38 Cano (2005) p. 8.

39 Rebollo (2005) p. 593.

40 García de Enterría y Fernández (2002) p. 579. 
recuérdese que ni siquiera la interposición de algún recurso administrativo o de una acción jurisdiccional suspenden por sí mismos la presunción de validez y la correlativa producción de los efectos jurídicos del acto administrativo impugnado, sino que se requiere de un pronunciamiento expreso de la Administración o del juez de la causa que excepcionalmente ordene la suspensión mientras se discute y se resuelve sobre la validez del acto $^{41}$.

Por otro lado, es menester señalar que la presunción de validez también permite personificar una especie de principio, que García de ENTERRía y FERNÁNDEZ denominan favor acti, y que, como bien lo explican ${ }^{42}$, no sólo viene a estructurar toda la teoría de la nulidades de los actos administrativos, sino que también le otorga a los actos administrativos una serie de técnicas de garantía de supervivencia, como son la incomunicación de los vicios a otras partes del acto o a otros actos no viciados, o la posibilidad de convalidar los actos viciados (así se desprende de los artículos 49.2 y 52 de la Ley $n^{0} 39$, de 2015), pero que, en resumen, vienen a articular la imposición a una tendencia a restringir las posibilidades de invalidación de los actos administrativos y que en su conjunto sirven para denotar la existencia de un principio de conservación del acto administrativo derivado de la presunción de su validez. Lo relevante, para nuestro estudio, y el por qué de la cita es que tales normativas se encuentran en gran medida, aunque con distinta técnica legislativa, replicadas en la LBPA. Así, por ejemplo, el principio de conservación del acto administrativo o la posibilidad de convalidación de los actos administrativos, conforme a la doctrina de la CGR, se encuentran recogidos en el ya mencionado Artículo 13 de la LBPA ${ }^{43}$. Por su parte, el Artículo 53 también de la LBPA dispone que la invalidación de un acto podrá ser parcial y que ésta no afectará las disposiciones que sean independientes de la parte invalidada ${ }^{44}$. De este modo, lo recientemente afirmado para el Derecho hispánico es también efectivo para el Derecho chileno.

41 En el Derecho chileno, así se deduce del ya transcrito inciso final del Artículo $3^{\circ}$ de la LBPA.

42 García de Enterría y Fernández (2002) p. 579.

43 El Dictamen CGR, $\mathrm{N}^{\circ}$ 64.86o de 2016, interpreta que el mencionado Artículo 13 no sólo contempla intrínsecamente el principio de conservación de los actos administrativos, sino que también la posibilidad de convalidarlos.

44 LBPA, Artículo 53. “(...) La invalidación de un acto administrativo podrá ser total o parcial. La invalidación parcial no afectará las disposiciones que sean independientes de la parte invalidada (...)". 
Sin embargo, lo expuesto no debe ser entendido como que la presunción de validez de los actos administrativos viene a significar un mero privilegio de las administraciones públicas para imponer sus decisiones, en desmedro de los particulares, sino que, por el contrario, debe razonarse que es el medio necesario e imprescindible para que las administraciones públicas puedan alcanzar, con las menores trabas posibles, los intereses generales y los fines propios que el ordenamiento jurídico les ha encargado resguardar y promover, sin necesidad de que el órgano administrativo que emitió un acto administrativo para tales fines tenga que recurrir a la jurisdicción para exigir su cumplimiento cada vez que alguien cuestione la validez de los mismos ${ }^{45}$. Esto es así sobre todo si se toma en consideración que esa fuerza vinculante, que se desprende de la mencionada presunción de validez, es entregada por un mandato expreso del ordenamiento jurídico a todos los actos administrativos, tal como lo dispone el inciso final del citado Artículo $3^{\circ}$ de la LBPA, y como bien lo ha razonado la Corte Suprema de Justicia, la presunción de validez se instaura en el Derecho chileno como una cualidad per se con la que están dotados todos los actos administrativos ${ }^{46}$. Así, finalmente, podemos afirmar que la presunción de validez tiene su principio en el ordenamiento jurídico como una atribución normativa, que luego se concretiza en la dictación de cada acto en particular y que, además, viene a dotar al acto administrativo de una fuerza que vincula a la obediencia del mismo y una tendencia a su conservación, a menos que la autoridad administrativa o el juez, en su caso, disponga que el acto adolece de un vicio de tal gravedad que implique la destrucción de la presunción de validez.

45 Lo inverso, obviamente, implicaría un grave perjuicio para los intereses generales, a los cuales las administraciones públicas están destinas a promover y resguardar. Así, por ejemplo, sólo es cosa de imaginarse los graves perjuicios que se producirían si algún particular pudiera dejar de cumplir, así sin más trámite, alguna disposición administrativa, como sería el caso de la veda de alguna especie animal en peligro de extinción, porque la considera ilegal, cuya inobservancia traería aparejado la pérdida definitiva o muy probablemente una disminución de la especie animal. $O$, imagínese el caso en que la autoridad sanitaria dispusiera alguna cuarentena para prevenir las difusiones de graves enfermedades o plagas y se le desobedeciera hasta que algún tribunal dispusiese lo contrario. Simplemente sería absurdo. 


\section{SOBRE EL INICIO Y FIN DE LA PRESUNCIÓN DE VALIDEZ}

\section{El inicio de la presunción de validez}

En cuanto este punto, el legislador chileno se apartó del régimen hispano, en el cual la presunción de validez tiene lugar desde que el acto se dicta ${ }^{47}$. En su lugar, dispuso que en el ordenamiento jurídico chileno el acto administrativo se presumirá válido en un momento posterior, es decir desde que éste entra en vigencia (Artículo $3^{\circ}$ de la LBPA). Vigencia que la doctrina chilena ha identificado que ocurre una vez cumplida la etapa de comunicación del respectivo procedimiento administrativo ${ }^{48}$. Es decir, el acto administrativo se presumirá válido desde que sea publicado o notificado, según corresponda. Esta situación nos lleva a otra inquietud, la que se origina por la circunstancia derivada de que la presunción de validez al iniciarse desde que el acto entra en vigencia implica que este último, aun cuando esté íntegramente dictado pero mientras no sea publicitado, no estará revestido de la presunción de validez. De ahí que se nos genera la duda sobre si es posible eliminar aquel acto que se estime irregular, por la misma Administración que lo dictó, sin necesidad de someterse al procedimiento administrativo de invalidación dispuesto en el Artículo 53 de la $\mathrm{LBPA}^{49}$. En efecto, pareciera que la respuesta es afirmativa, pues así se desprende de esta mencionada norma, la que establece -entre sus presupuestos de hecho para operar- que no hayan trascurrido más de dos años desde que se notificó o publicó el acto que se pretende invalidar. De este modo, comprendemos que si no ha habido publicidad del acto, es decir mientras éste no ha entrado en vigencia, las administración públicas

47 En cuanto al ordenamiento jurídico español, la regla es que un acto dictado, aunque no esté notificado o publicado, si se quiere modificar o eliminar por adolecer de algún vicio invalidante, se debe acudir a los procedimientos de revisión, pues por imposición del Artículo 39 de la Ley $n^{\circ} 39$, de 2015, todo acto administrativo desde que se ha dictado ya está revestido de la presunción de validez. Así lo destaca, por ejemplo, Fernández (2014), p. 506.

48 Moraga (2010) p. 249.

49 Si bien el procedimiento administrativo de invalidación que contempla el mencionado Artículo 53 de la LBPA es algo escueto, por lo menos establece ciertas exigencias relevantes para la protección de los derechos de las personas. Así, destaca como una condición indispensable y previa para emitir válidamente la declaración de invalidez, que el particular afectado sea citado a una audiencia en la cual pueda expresary fundamentar su postura. Sobre el particular, la Corte Suprema, Sociedad Agrofuturo Limitada contra Servicio Agrícola y Ganadero de La Región del Bío-Bío (2011, rol n 6.070-2011), considerando $7^{\circ}$, ha resuelto que dicha citación es un requisito esencial, que de faltar, a su vez, vicia el procedimiento administrativo de invalidación. 
chilenas no se hallan en la necesidad de tener que invalidar con íntegra sujeción a las exigencias que impone la citada norma, sino que bastará que el órgano administrativo que dictó el acto, simple y llanamente, así lo disponga. Precisamente, este ha sido el criterio de la CGR, la cual ha señalado que "(...) se colige que el procedimiento de invalidación procede respecto de un acto administrativo contrario a Derecho que ha sido notificado o publicado, según corresponda, ya que sólo en tal caso éste será apto para producir efectos, pues no debe perderse de vista que la invalidación constituye, en esencia, un mecanismo por el cual se extingue la eficacia de un acto de la Administración por razones de ilegalidad, de modo que la aplicación de dicha institución jurídica carece de sentido cuando la actuación en cuestión no ha podido causar efectos, como ocurre en esta situación (...)" ${ }^{\prime 50}$. Analizar esto nos parece de relevancia, pues si además se considera que parte de la doctrina chilena afirma que el acto administrativo no ha sido elaborado plenamente, mientras no sea publicitado, en atención a que entiende que los actos realizados en la etapa de comunicación son actos de mero trámite $y$, aunque posteriores al acto decisorio, se entienden igualmente integrados al acto decisorio ${ }^{51}$. Y todos estos en su conjunto recién forman el acto administrativo propiamente $\mathrm{ta}^{52} \mathrm{y}$, por ende, el único que gozaría de la presunción de validez. Es por ello que en nuestra opinión y con vista especialmente hacia el administrado, como también con el fin de generar una alerta al respecto, el régimen legal y doctrinal chileno referido se erige con un elevado riesgo de afectar la seguridad jurídica, pues fácilmente puede ocurrir que aquel destinatario expectante con la confección de algún acto administrativo que lo beneficie vea frustrada su aspiración con algún cambio de parecer de la Administración que dictó el acto, la cual quizás aduciendo la existencia de algún vicio, lo habrá eliminado así sin

50 CGR, Dictamen $\mathrm{N}^{\circ}$ 50.318, de 2015.

51 Cfr. Bocksang (2003) pp. 15-32, Moraga (2010) pp. 241 y 242 o Soto (2003) p. 83.

52 BOCKSANG (2009) p. 195. En una posición extrema, según nuestro parecer, critica el uso de la terminología dictación para la elaboración de los actos administrativos en Chile, pues este autor considera que no se debe confundir al acto terminal con el acto decisorio, en atención a que este último en el sistema chileno habría sido confinado a la condición de un acto trámite más y por ende el acto administrativo no se dictaría, "sino que se constituye, una vez que todos sus componentes se han ordenado a él-esto es, cuando el procedimiento se ha consolidado formal y materialmente-, el llamado acto terminal nace a la vida del derecho". Empero, discrepamos de dicha postura, pues aquello expresa una incorrecta interpretación de la ley. En efecto, a nuestro entender, para la LBPA el acto administrativo existe desde que se dicta, según se desprende de los arts. 18 y 40. Así, cosa distinta es que tanto la presunción de validez como la eficacia, por mandato legal (artículos $3^{\circ}$ y 51 ), surjan después, es decir desde que el acto entre en vigencia por medio de su notificación o publicación, según corresponda. 
más trámite o muy probablemente sin que el afectado tenga conocimiento de aquello o, al menos, sin la oportunidad de poder ejercer las garantías que el procedimiento administrativo de invalidación dispone para tales efectos (Artículo 53 de la LBPA). Así, por ejemplo, puede ocurrir que un particular que haya tomado conocimiento, primero, del acto trámite que lo sitúe como el mejor postor para que se le adjudique la celebración de algún contrato público y, después, luego de dictado el acto administrativo decisorio (que es el que en definitiva dispondrá aprobar la adjudicación), éste sea eliminado por la misma autoridad administrativa que lo dictó antes de que se le notifique o publique, quizás porque efectivamente existirían motivos de legalidad para ello, pero sin que el particular afectado pudiera alegar algo en su favor. Situación que según el parecer de la CGR sería correcta, pues el acto, al no haber entrado en vigencia, carece de la presunción de validez y por consiguiente de su protección ${ }^{53}$.

\section{El fin de la presunción de validez}

Como se señaló al principio de este trabajo, la presunción de validez es una presunción de aquellas conocidas como iuris tantum o, en los términos del Código Civil chileno, presunción meramente legal ${ }^{54}$. Esto quiere decir que admite la eventualidad de ser impugnada y destruida mediante los mecanismos que concede el ordenamiento jurídico para tales efectos. $\mathrm{O}$, en otras palabras, la presunción de validez subsiste hasta que los interesados, con posterioridad a la elaboración del acto, soliciten a la autori-

53 Esto ha ocurrido en una situación planteada ante la CGR, respecto a la eliminación mediante un simple retiro de un acto administrativo que disponía adjudicar a un particular la celebración de un determinado contrato público. En dicho dictamen, la CGR da la razón a la Administración respecto a que, sin someterse a un procedimiento de invalidación, era correcto eliminar el acto de adjudicación antes de que éste entrara en vigencia. Esta explicación resulta de la aplicación de la doctrina imperante en Chile, que estima que no existe el acto administrativo mientras éste no entre en vigencia y por ende carece de la cobertura de la presunción de validez. Así se deduce del Dictamen no 41.269, de 2017, que expresó: “(...) En este contexto, es necesario recordar que en el concurso público de que se trata, la Dirección General de Obras Públicas comunicó su intención de adjudicarle la citada concesión al grupo licitante, dictando yenviando posteriormente el respectivo acto administrativo a trámite de control preventivo de juridicidad, el que fue luego retirado de este ente de control sin que, sin embargo, llegase en definitiva a existir un decreto que adjudicara la concesión en los términos de los artículos $8^{\circ}$ y 28 de la Ley y Reglamento de Concesiones de Obras Públicas, respectivamente, según los cuales el contrato se perfeccionará-y se entenderá adjudicado - una vez publicado en el Diario Oficial el decreto supremo respectivo (...)".

54 Código Civil, Artículo 47. 
dad administrativa, mediante el ejercicio de su potestad invalidatoria, o un juez, en virtud de sus facultades jurisdiccionales, que declaren que el acto administrativo es inválido.

Desde luego, es pertinente destacar que la declaración de invalidez, o sea aquella "(...) calificación jurídica que alude a la disconformidad entre un acto y el esquema para él previsto por el ordenamiento $(. . .)^{\prime \prime 55}$, es la única forma para echar abajo la presunción de validez, pues no cabe confundir la eliminación del acto administrativo mismo con la eliminación de la presunción de validez, la cual únicamente ocurrirá cuando se ha declarado que el acto es inválido por adolecer de un vicio de magnitud invalidante.

En efecto, la doctrina hispana también nos ilustra en este aspecto ${ }^{56}$, pues nos precisa que la presunción de validez no desaparece cuando el acto administrativo se ha extinguido por razones naturales, como en aquel caso en que se cumplió el objetivo para el cual fue elaborado el acto y por ende éste se agotó, ni tampoco por otras causas provocadas, que no sea la anulación, como cuando el acto ha sido revocado por motivos de oportunidad, mérito o conveniencia, pues en todos estos casos el acto solamente deja de producir nuevos efectos, pero no afecta a la presunción de validez, pues como bien lo explica Rebolto, "tras esa pérdida de eficacia, habrá que seguir presumiendo válido aquel acto, con lo que ello comporta para los efectos que en su momento produjo o debió producir ${ }^{\prime \prime 57}$.

Respecto a la realidad chilena, la comprensión sobre la materia en estudio no parece distinta. Así se deduce de la jurisprudencia de la Corte Suprema que ha señalado que la presunción de validez se desvirtúa exclusivamente demostrando la existencia de algún vicio de invalidez. Por ejemplo, dicho tribunal ha señalado que"(...) no existe duda de que el Municipio actúo en el marco del cometido de protección y preservación del patrimonio cultural comunal que le ha otorgado la ley y su propia ordenanza local, ejecutando actos administrativos que, en tal calidad, gozan de presunción de legalidad. Corresponde a la reclamante desvirtuar tal presunción, acreditando la ilicitud del actuar edilicio, o la desviación de poder, o el carácter arbitrario del uso de

\footnotetext{
55 CANO (2005) p. 16.

56 ReBollo (2005) p. 595.

57 Ídem.
} 
tales facultades legales (...)" ${ }^{\prime \prime 5}$. En efecto, tal como se puede observar en el considerando transcrito, todas sus palabras hacen referencia a vicios o irregularidades que pueden generar la invalidez del acto administrativo, pero no a otro tipo de causal de extinción como son aquellas relativas al mérito, conveniencia o cambio de circunstancias fácticas o legales. De ahí que también le hallamos la razón a lo expresado por BERMúDEZ, en cuanto a que se puede concluir que "con la entrada en vigor de la LBPA, los actos administrativos son legales (válidos en nuestra opinión) mientras no se diga lo contrario por el juez o por la propia Administración del Estado en un procedimiento que tenga como resultado su invalidación" ${ }^{59}$ y que por ende, agregamos, destruirá su presunción de validez.

\section{LA PRESUNCIÓN DE VALIDEZ CON RESPECTO A LAS ADMINISTRACIONES PÚBLICAS Y LOS TRIBUNALES DE JUSTICIA}

Tal como lo hemos afirmado precedentemente, el Derecho chileno reviste a los actos administrativos desde que han entrado en vigencia con una presunción de validez (Artículo $3^{\circ}$ de la LBPA), la cual más allá de ser sólo una mera suposición de legalidad, su real contexto es la determinación de un valor jurídico, el que se inicia con la premisa de que la ley da por sentado que el acto administrativo es válido y se termina con la conclusión que éste vincula a la obediencia del mismo ${ }^{60} \mathrm{e}$ impone una tendencia más a su conservación que a su destrucción. Mandatos que no sólo vinculan a los particulares, como uno se podría imaginar, sino que también a las administraciones públicas y a los tribunales de Justicia. Entonces, cómo se explica la circunstancia que aquel acto administrativo que la ley lo ha presumido válido, luego de haber entrado en vigencia, se pueda eliminar por la misma Administración que lo dictó o por medio de una sentencia judicial.

58 Corte Suprema, González, Arellano, Civanco y Otros contra Ilustre Municipalidad de Santiago (2016, rol n ${ }^{\circ}$ 22.944-2016), considerando $18^{\circ}$.

59 Bermúdez (2010) p. 107. El paréntesis es nuestro.

60 García de Enterría y Fernández (2002) pp. 513 y 514. 
En primer lugar, y con respecto a las administraciones públicas, es menester precisar que la respuesta se orienta por razonar que la presunción de validez liga a las administraciones públicas con un deber de obediencia a lo establecido por el acto y obviamente debe preferir optar por su conservación, tratando en lo posible de subsanar el acto, más que buscar su eliminación. Esto se debe comprender que es una regla general y, por ende, como toda regla general admite excepciones ${ }^{61}$, pues sería errado concebir que la existencia de la presunción de validez viene a constituir un obstáculo para que la Administración que dictó el acto lo pueda eliminar, sobre todo si, luego del análisis que en cada caso se realice, se ha cotejado la existencia de vicios groseros o de tal magnitud que aconsejen su eliminación. En efecto, así también lo ha puesto de manifiesto la jurisprudencia administrativa de la CGR, la que ha expresado que "...) en cuanto (a la consulta sobre) la improcedencia de dejar sin efecto la incorporación del afectado en la lista anual de retiros, pues el pertinente acto administrativo goza de presunción de legalidad, conforme con lo previsto en el artículo $3^{\circ}$ de la ley $N^{\circ} 19.880$, (esta CGR) cumple con aclarar que ello no es óbice para que la autoridad ejerza su potestad invalidatoria cuando se compruebe un vicio que incida en su licitud, lo que aconteció en la especie (...)" $(\mathrm{sic})^{62}$. Asimismo, la CGR ha completado ese criterio y ha indicado que la declaración de invalidez, y por ende la destrucción de la presunción de validez, procede inclusive en aquellos casos en que el acto ha aprobado controles preventivos de legalidad, como es el trámite de toma de razón de los actos administrativos contenidos en decretos o en resoluciones ${ }^{63}$.

Por consiguiente, a nuestro juicio, admitir lo contrario, es decir que la presunción de validez torna al acto administrativo en inmutable a todo

61 En efecto, JARA (2004) p. 128, explica que las administraciones públicas no deben invalidar un acto administrativo por solo existir alguna mera ilegalidad, sino que deben realizarlo excepcionalmente y en la medida que esa ilegalidad impida que el acto alcance un fin que el derecho en su conjunto considere digno de protección.

62 CGR, Dictamen N 85.076, de 2016. Los paréntesis son nuestros.

63 CGR, Dictamen $\mathrm{N}^{\circ}$ 29.826, de 2006. "Al respecto, cumple señalar, en primertérmino, que el control preventivo realizado por este organismo fiscalizador a través de la toma de razón otorga (refuerza en nuestra opinión, pues recuérdese que es la ley la que otorga tal presunción) a los actos administrativos sujetos a dicho trámite, una presunción de legalidad que permite que ellos deban acatarse tanto por las autoridades como por los particulares a quienes afecta. Sin embargo, dicho supuesto de juridicidad no resulta inmutable si con ocasión de una revisión ulterior, a la luz de elementos de juicio o antecedentes no considerados en el referido control previo, aparecen vicios de legalidad, en cuyo caso el acto irregular deberá dejarse sin efecto por la autoridad que lo emitió en consideración al principio de juridicidad establecido en los artículos $6^{\circ} y 7^{\circ}$ de la Constitución Política". 
evento para la Administración que lo dictó, sería ir en contra del sentido común y significaría desatender la interpretación sistemática y armónica que debe darse a las normas que componen la LBPA. Normas que, por lo demás, han facultado a las administraciones públicas con una potestad invalidatoria para retirar aquellos actos administrativos que, según su parecer, sean contrarios a Derecho ${ }^{64}$. En este sentido, cabe precisar que si una autoridad administrativa se ha percatado de la existencia de vicios invalidantes en un determinado acto que dictó y éste está vigente, en virtud de la presunción de validez de la que goza dicho acto, ésta no podrá llegar y sin más trámites retirar o dejar de cumplir aquel acto porque lo estima ilegal o viciado, sino que necesariamente deberá iniciar el correspondiente procedimiento administrativo de revisión tendiente a destruir la presunción de validez que lo ampara ${ }^{65} y$, mientras tanto no se resuelva y se declare la invalidación del acto, para paralizar la eficacia del mismo, a su vez, deberá disponer la suspensión de sus efectos, conforme se deduce de la interpretación armónica de los ya mencionados artículos $3^{\circ}$ y 53 de la LBPA.

En segundo lugar, en cuanto a los tribunales de Justicia, la presunción de validez no es un mandato que les afecte directamente, toda vez que estos últimos no son los destinatarios ni los obligados por los actos administrativos que se emitan, sino más bien, en virtud de su función netamente jurisdiccional, son los llamados a disipar en definitiva sobre si un determinado acto administrativo es válido o no ${ }^{66}$. Es decir, les corresponde dirimir si subsiste o se destruye la presunción de validez, según el resultado

64 Ley n 19.880, de 2003, Artículo 53. "Invalidación. La autoridad administrativa podrá, de oficio o a petición de parte, invalidar los actos contrarios a derecho, previa audiencia del interesado, siempre que lo haga dentro de los dos años contados desde la notificación o publicación del acto $(. . .)^{\prime \prime}$.

65 En efecto, así también lo ha razonado la Corte Suprema, en sentencia Grupo CAVALA S.A. contra Ilustre Municipalidad de Independencia (2016: rol n $\left.^{\circ} 22.230-2016\right)$, considerando $4^{\circ}$, que ha señalado lo siguiente: "(...) resulta evidente que si la Municipalidad de Independencia estimó que había incurrido en una ilegalidad al dictar el Decreto Alcaldicio $N^{\circ} 5.248$, de 23 de noviembre de 2015, por el que había autorizado a la sociedad recurrente a instalar un letrero tipo led en un bien nacional de uso público, lo que procedía hacer era iniciar un procedimiento de invalidación, en el que se otorgara al interesado la posibilidad de ser oído, lo que no aconteció en la especie, en cuanto se limitó a citar al representante de la sociedad recurrente a una reunión informativa, sin que conste que en ella se le haya permitido efectuar sus alegaciones y descargos".

66 Ley $^{\circ}$ 19.880, de 2003, Artículo 54, inciso final. "Si respecto de un acto administrativo se deduce una acción jurisdiccional por el interesado, la Administración deberá inhibirse de conocer cualquier reclamación que éste interponga sobre la misma pretensión". 
que se consigne en el respectivo fallo. Sin embargo, y en razón de esto último, es menester señalar que nos parece acertado considerar que la presunción de validez de los actos administrativos también vincula a los tribunales de Justicia, aunque de un modo indirecto como se pasa a explicar.

En efecto, la presunción de validez de los actos administrativos, necesariamente, es un antecedente que el juez de la causa deberá tener en cuenta al momento de resolver sobre el asunto litigioso, y en el evento que le sea requerida, deberá ponderar si corresponde disponer una orden de suspensión de los efectos del acto impugnado en su sede, pues debe partir de la base que el acto administrativo refutado en su sede, por disposición del ordenamiento jurídico, se supone válido, y esto se debe entenderse así por todos, inclusive por el juez, hasta que no se declare en definitiva la invalidez. De manera que durante el proceso judicial se deberá tener en consideración que el objetivo del juicio y el análisis del mismo se deberá centrar en la constatación de la existencia de un vicio de tal magnitud que, siendo lo suficientemente grave, aconseje la destrucción del acto administrativo. Es decir, la presunción de validez tiene que ser tenida en cuenta por el juez al momento de decidir ${ }^{67}$. Sobre el particular, la Corte Suprema de Justicia nos da la razón al revocar una sentencia que desatendió la presunción de validez de los actos administrativos, conforme se deduce del siguiente extracto.

“(...) DÉCIMO PRIMERO: Que al decidir de ese modo los sentenciadores de segunda instancia quebrantaron, además, lo prevenido en el artículo 3 de la Ley $n^{\circ} 19.880$, puesto que con ello desconocieron la presunción de validez (...).

DÉCIMO SEGUNDO: Que, en efecto, la decisión de los jueces de segundo grado supone desconocer la señalada presunción de legalidad del acto administrativo y, además, la facultad de que está investida la autoridad para disponer por sí misma su ejecución, pues se ha negado valor a una determinación adoptada por la autoridad en uso de las facultades que le son propias (...).

DÉCIMO CUARTO: Que en la medida que los jueces de la instancia no aplicaron correctamente los referidos preceptos legales, en cuanto son los que regulan la cuestión sometida a su conocimiento, cometieron los errores de Derecho que se les atribuyen en el recurso vulnerando por falta de aplica-

67 Rebollo (2005) p. 606. 
ción del artículo 3 de la Ley $n^{\circ} 19.880$ y por falsa aplicación de los artículos 19, 1489 y 1545 del Código Civil, motivo por el que el arbitrio en examen ha de ser acogido (...)" 68 .

De ahí que entender que la presunción de validez no vincula en lo absoluto a los tribunales de Justicia es en realidad una errada comprensión del verdadero sentido y efecto que posee la presunción de validez, la cual -como se ha expuesto a lo largo de este trabajo- configura toda la teoría de los actos administrativos, imponiendo como regla general una tendencia a optar por la conservación de estos últimos.

\section{CONCLUSIONES}

En síntesis, presunción de legalidad y presunción de validez, en su correcto significado, no son un mismo instituto, aunque tanto la doctrina, la jurisprudencia y las normas en ocasiones usan ambos enunciados como si se tratasen de sinónimos. Asimismo, conforme a un estudio sistemático de las diversas normas que componen a la LBPA, la interpretación correcta que se debe dar a su artículo $3^{\circ}$ es que el legislador ha situado en el ordenamiento jurídico chileno a la institución de la presunción de validez de los actos administrativos en su estricto rigor, no obstante se haya expresado con un léxico inconveniente, a nuestro parecer, a la presunción de legalidad.

Por otro lado, se ha determinado que la presunción de validez no consiste en una mera suposición de legalidad, sino que su cualidad esencial es la de revestir a los actos administrativos con una fuerza vinculante y una tendencia a su conservación, que impone un deber de acatamiento de los efectos producidos por el acto administrativo, que se justifica por la circunstancia de que al dar por sentado que el acto es válido implica que éste se deberá cumplir, en tanto no sean suspendidos sus efectos por la autoridad administrativa o juez competente, según corresponda, y hasta que finalmente se resuelva que el acto adolece de un vicio de tal gravedad que implique la destrucción de la presunción de validez.

68 Corte Suprema, Sociedad de Proyectos y Servicios Ingeniería Limitada contra Gobierno Regional de Tarapacá (2015, rol n 1.126-2015). 
En cuanto al comienzo, se ha puesto de manifiesto que la presunción de validez en el Derecho chileno tiene su inicio desde que el acto ha entrado en vigencia y no desde que ha sido dictado, lo que trae como consecuencia que mientras el acto no esté vigente, no estará revestido de la presunción de validez. De este modo, en caso que presente vicios relevantes que aconsejen su expulsión del ordenamiento, no será un imperativo para la Administración que lo dictó retirarlo por medio del procedimiento administrativo de revisión establecido para tales efectos, sino que bastará una simple eliminación.

Simultáneamente, se ha determinado que la presunción de validez no desaparece cuando el acto administrativo se ha extinguido por razones naturales, como cuando se ha cumplido el objetivo del acto, ni tampoco por causas provocadas, que no sea la declaración de invalidez, pues se ha destacado que no se debe confundir la eliminación del acto administrativo, que admite muchas más variedades, con la destrucción de la presunción en comento, que como insistimos se restringe a los casos de invalidación o anulación.

Finalmente, se ha asentado que si bien la presunción de validez importa un mandato a la obediencia de los efectos de los actos administrativos, como también a preferir su conservación, aquello no implica que las administraciones competentes no puedan incoar un procedimiento administrativo destinado a obtener la respectiva declaración de invalidez cuando se han percatado de vicios graves. Con respecto a los tribunales de Justicia, la presunción de validez es un antecedente que el juez de la causa, necesariamente, deberá tener en cuenta al momento de decidir. Primero, sobre el mérito para disponer la suspensión de los efectos del acto y, segundo, sobre la eliminación del mismo, ya que éste debe partir de la base que el acto administrativo impugnado en su sede, por un mandato del legislador, se supone válido mientras no se constate y consecuencialmente se declare la invalidez. 


\section{BIBLIOGRAFÍA CITADA}

Aguerrea, Pedro (2003). "Las prerrogativas del acto administrativo en la Ley $n^{\circ}$ 19.880", en La Ley ${ }^{\circ}$ 19.880, sobre procedimientos administrativos, Conferencias Santo Tomás de Aquino (Santiago, Universidad Santo Tomás), pp. 45-50.

ARóstICA, Iván (1991): ¿Qué queda de la presunción de legalidad?", Revista de Derecho y Jurisprudencia y Gaceta de los Tribunales, Santiago, Vol. 88, $\mathrm{n}^{\circ} 1$.

BERMÚDEZ, Jorge (2010): "Estado actual del control de legalidad de los actos administrativos ¿Qué queda de la nulidad de Derecho Público?", Revista de Derecho de la Universidad Austral de Chile, Vol. 23, n 1, pp. 103-123.

_- (2011): Derecho Administrativo General (Segunda Edición, Santiago, Editorial Legal Publishing).

Biblioteca del Congreso Nacional (2003): "Historia de la Ley $n^{\circ}$ 19.880, que establece la base de los procedimientos administrativos que rigen los órganos de la administración del Estado". Disponible en <http://www. bcn.cl/historiadelaley/nc/historia-de-la-ley/5844/>.

BOCANEGRA, Raúl (2012): Lecciones sobre el acto administrativo (Cuarta Edición, Pamplona, Editorial Aranzadi).

BoCKSANG, Gabriel (2003): “¿Cuál es el acto terminal del procedimiento administrativo?", en Soto, Eduardo (edit.), Conferencias Santo Tomás de Aquino. La Ley 19.880, sobre procedimientos administrativos (Santiago, Universidad Santo Tomás), pp. 15-32.

- (2009): El procedimiento administrativo chileno, estudio analítico y sistemático de coherencia (Segunda Edición, Santiago, Editorial Legal Publishing).

BOQUERA, José (1993): Estudios sobre el acto administrativo (Séptima Edición, Madrid, Editorial Civitas S.A.). 
CAMACHO, Gladys (2013): "El concepto de acto administrativo", VV.AA. Bocksang Hola, Gabriel y Lara Arroyo, José Luis (coords.), Procedimiento administrativo y contratación pública. Estudio a diez años de entrada en vigencia de las leyes $N^{\circ} 19.880$ y $N^{\circ} 19.886$ (Santiago, Editorial Thomson Reuters), pp. 63-90.

CANO, Tomás (2004): La invalidez sobrevenida de los actos administrativos (Madrid, Civitas Ediciones S.L.).

- (2005): "La invalidez de los actos administrativos y sus consecuencias", en Revista General de Derecho Administrativo, Vol. n 8.

Droml, Roberto (2008): El acto administrativo (Cuarta Edición, Buenos Aires-Madrid-México, Editorial Ciudad Argentina-Hispania Libros).

Esteve, José (2012): Lecciones de Derecho Administrativo (Segunda Edición, Madrid, Editorial Marcial Pons).

FERNÁNDEZ, Germán (2014): El sistema de Derecho Administrativo (Segunda Edición, Pamplona, Editorial Aranzadi).

García de Enterría, Eduardo y Fernández, Tomás-Ramón (2002): Curso de Derecho Administrativo I (Undécima Edición, Madrid, Editorial Civitas S.L.).

JARA, Jaime (2004): La nulidad de Derecho Público ante la doctrina y la jurisprudencia (Santiago, Editorial Libromar).

Madariaga, Mónica (1993): Seguridad jurídica y administración pública en el siglo XXI (Segunda Edición, Santiago, Editorial Jurídica de Chile).

MARín, Urbano (2002): "Vigencia actual de la invalidación de los actos administrativo", Revista de Derecho del Consejo de Defensa del Estado, $\mathrm{n}^{\circ}$ 2. Disponible en: <https://www.cde.cl/wps/wcm/connect/ 185do4b4-96ad-46ab-a207-adec82b25feg/3.pdf?MOD=AJPERES>.

MILLAR, Javier (2008): La potestad invalidatoria en el Derecho chileno (tesis doctoral) (Santiago, Universidad de Chile, Facultad de Derecho). 
Moraga, Claudio (2010): Tratado de Derecho Administrativo. La actividad formal de la Administración del Estado, Tomo VII (Santiago, Editorial Abeledo Perrot-Legal Publishing).

Olguín, Hugo (1961): Extinción de los actos administrativos: revocación, invalidación y decaimiento (Santiago, Editorial Jurídica de Chile).

Pierry, Pedro (2005): "El concepto de acto administrativo en la ley de procedimientos administrativos. El Reglamento. Dictámenes de la Contraloría General de la República", Revista de Derecho del Consejo de Defensa del Estado, vol. XIII. Disponible en: <https://www.cde. $\mathrm{cl} / \mathrm{wps} / \mathrm{wcm} / \mathrm{connect} / 14$ bo181a-aO31-47f3-a12a-825285f51a7e/5. pdf?MOD=AJPERES $>$.

Rebollo, Manuel (2005): "La presunción de validez", Revista española de Derecho Administrativo, Vol. 128, pp. 587-638.

- (2009): "La nulidad en Derecho Administrativo (Consideración de su significado y régimen en el actual Derecho administrativo español a propósito de la nulidad de los derechos fundamentales)", Revista Justicia Administrativa, Vol. $\mathrm{n}^{\circ}$ 44, pp. 5-39.

- (2016): "La invalidez del acto administrativo", en VV.AA. Rebollo Puig, Manuel y Carbonell Porras, Eloísa (coords.), Derecho administrativo, Tomo II: Régimen jurídico básico y control de la Administración (Madrid, Editorial Tecnos), pp. 99-119.

RIVEROS, Beatriz (2006): “La presunción de legalidad del acto administrativo: el artículo $3^{\circ}$ de la Ley $n^{\circ} 19.880$ de procedimientos administrativos a la luz de la Constitución de 1980", Revista lus Publicum, Vol. n 16, pp. 117-124.

SILVA, Enrique (1995): Derecho administrativo chileno y comparado. Actos, contratos y bienes (Primera Edición, Santiago, Editorial Jurídica de Chile).

Soтo KLoss, Eduardo (1996): Derecho Administrativo, Bases Fundamentales, Tomo II (Santiago, Editorial Jurídica de Chile). 
__ (2003): “La Ley 19.880, sobre procedimientos administrativos, ¿Aleluya o Miserere?", en Sото Kıoss, Eduardo (edit.), Conferencias Santo Tomás de Aquino. La Ley 19.880, sobre procedimientos administrativos (Santiago, Universidad Santo Tomás), pp. 75-106.

— (2010): "Sobre la pretendida presunción de legalidad de los actos administrativos: otro resabio de monarquías absolutas", en Gaceta jurídica, Santiago, Vol. $\mathrm{n}^{0} 366$.

VERGARA, Alejandro (2013): "Vicios de procedimiento o de forma que no afectan la validez del acto administrativo", VV.AA. FerRADA BóRQUEZ, Juan Carlos (coord.), La nulidad de los actos administrativos en el Derecho chileno (Santiago, Editorial Legal Publishing), pp. 267-283.

\section{NORMAS JURÍDICAS CITADAS}

Código Civil, del 14 de diciembre de 1855 .

Constitución Política de la República de Chile, del 8 de agosto de 1980.

Ley $\mathrm{n}^{\mathrm{O}} 19.880$, del 29 de mayo de 2003, que establece bases de los procedimientos administrativos.

Ley Nacional de Procedimientos Administrativos $\mathrm{N}^{\circ}$ 19.549, del 27 de abril de 1972 (Argentina).

Ley $n^{\circ}$ 30, del 26 de noviembre de 1992, que establece el Régimen Jurídico de las Administraciones Públicas y del Procedimiento Administrativo Común (modificada por Real Decreto-ley no 8/2011, de 1 de julio de 2011) (España).

Ley $\mathrm{n}^{\circ}$ 39, del 1 de octubre de 2015, del Procedimiento Administrativo Común de las Administraciones Públicas (España). 


\section{JURISPRUDENCIA CITADA}

Tribunal Constitucional, sobre pronunciamiento de oficio sobre la inconstitucionalidad del inciso primero del artículo 171 del Código Sanitario (2009): 25 de mayo de 2009, rol n 1345-2009.

Corte Suprema, Sociedad Agrofuturo Limitada contra Servicio Agrícola y Ganadero de la Región del Bío-Bío (2011): 6 de octubre de 2011, rol no 6.070-2011.

Corte Suprema, Sociedad Química y Minera de Chile S.A. contra Comisión de Evaluación Ambiental de la Región de Tarapacá (2015): 6 de abril de 2015, rol n 21.993-2014.

Corte Suprema, Sociedad de Proyectos y Servicios Ingeniería Limitada contra Gobierno Regional de Tarapacá (2015): 20 de agosto de 2015, rol n ${ }^{\circ}$ 1.126-2015.

Corte Suprema, Ilustre Municipalidad de La Reina contra Inversiones Aguas Claras S. A. (2015): 27 de octubre de 2015, rol n 6.237-2015.

Corte Suprema, Grupo CAVALA S.A. contra Ilustre Municipalidad de Independencia (2016): 16 de agosto de 2016, rol n 22.230-2016.

Corte Suprema, González, Arellano, Civanco y Otros contra Ilustre Municipalidad de Santiago (2016): 20 de diciembre de 2016, rol n 52.944-2016.

Contraloría General de la República, Dictamen n² 29.826, del 27 de junio de 2006.

Contraloría General de la República, Dictamen $n^{\circ} 41.269$, del 24 de noviembre de 2017.

Contraloría General de la República, Dictamen n 44.041, del 21 de septiembre de 2005.

Contraloría General de la República, Dictamen n ${ }^{\circ}$ 50.318, del 23 de junio de 2015. 
Contraloría General de la República, Dictamen n 64.860, del 1 de septiembre de 2016.

Contraloría General de la República, Dictamen n 85.076, del 24 de noviembre de 2016. 